\title{
EFEKTIFITAS PELAKSANAAN TUGAS DAN \\ WEWENANG DINAS KEHUTANAN DAN \\ PERKEBUNAN KOTA PALOPO MENURUT \\ PERATURAN DAERAH NOMOR 3 TAHUN 2008 \\ TENTANG PEMBENTUKAN, ORGANISASI DAN \\ TATA KERJA DINAS DAERAH KOTA PALOPO
}

Hisma Kahman

Fakultas Hukum Universitas Andi Djemma Palopo

\begin{abstract}
The purpose of this study are: to analyze the effectiveness of the implementation of duties and authority of the Forestry and Plantation Office of Palopo City according to Regional Regulation No. 3 of 2008; and Analyzing the factors that affect the implementation of the tasks and authorities of the Palopo City Forestry and Plantation Office. This research is descriptive research with empirical and normative juridical approach. The results showed that the implementation of duties and authority of the Office of Forestry and Plantations of Palopo City implemented less effective according to Regulation no. 3, 2008, including the task of assisting the Mayor in the administration of the governmental administration in the field of forestry and plantation, as well as the implementation of functions that are also implemented ineffective, including: (a) the formulation of technical policies in the field of forestry and plantations in accordance with the scope of their duties; (b) implementation of supervision and public services; (c) guidance to the Technical Implementing Unit of the Service; (d) the implementation of other duties in accordance with applicable legislation. Furthermore, factors affecting the effectiveness of the implementation of authority of Forestry and Plantation Office of Palopo City are: legal substance (56\%), legal structure (54\%), knowledge.
\end{abstract}

Keywords:

Law Enforcement, Disnakertras.

\begin{abstract}
Abstrak
Tujuan penelitian ini adalah: untuk menganalisis efektifitas pelaksanaan tugas dan wewenang Dinas Kehutanan dan Perkebunan Kota Palopo menurut Peraturan Daerah Nomor 3 Tahun 2008; dan Menganalisis faktor-faktor yang mempengaruhi pelaksanaan tugas dan wewenang Dinas Kehutanan dan Perkebunan Kota Palopo.
\end{abstract}


Penelitian ini adalah penelitian deskriptif dengan pendekatan yuridis empiris dan normati. Hasil penelitian menunjukkan bahwa pelaksanaan tugas dan wewenang Dinas Kehutanan dan Perkebunan Kota Palopo terlaksana kurang efektif sesuai Perda No. 3 Tahun 2008, termasuk tugas membantu Walikota dalam penyelenggaraan teknis pemerintahan di bidang kehutanan dan perkebunan, dan begitu pula pelaksanaan fungsi yang juga terlaksana kurang efektif, termasuk: (a) perumusan kebijakan teknis dalam bidang kehutanan dan perkebunan sesuai lingkup tugasnya; (b) pelaksanaan pengawasan dan pelayanan umum; (c) pembinaan terhadap Unit Pelaksana Teknis Dinas; (d) pelaksanaan tugas lain sesuai perundang-undangan yang berlaku. Selanjutnya faktor-faktor yang mempengaruhi efektifitas pelaksanaan kewenangan Dinas Kehutanan dan Perkebunan Kota Palopo adalah: substansi hukum (56\%), struktur hukum (54\%), pengetahuan.

\section{Kata Kunci:}

Penegakan Hukum, Disnakertras.

\section{A. PENDAHULUAN}

\section{Latar Belakang Masalah}

$\mathrm{H}$ utan mempunyai peranan sebagai penyerasi dan penyeimbang lingkungan global, yaitu sebagai paru-paru dunia, dimana keseimbangan hutan di suatu wilayah saja mampu membawa implikasi secara besar di tingkatan dunia. Indonesia merupakan salah satu negara yang memiliki hutan tropis terluas kedua di dunia. Indonesia memiliki hutan seluas kurang lebih 20,35 juta ha. Hutan itu diperinci dalam hutan produksi seluas 49,3 juta ha, hutan lindung seluas 39,9 juta ha, dan hutan konservasi dan hutan lainnya seluas 29,0 juta ha (Arifin, 2001).

Hutan mempunyai kedudukan dan peran yang sangat penting dalam menunjang pembangunan nasional yang memiliki manfaat yang nyata bagi kehidupan dan penghidupan bangsa Indonesia. Dalam kedudukannya sebagai salah satu penentu sistem penyangga kehidupan, hutan telah memberikan manfaat yang besar bagi umat manusia. Oleh karena itu, hutan harus dijaga kelestariannya dimana pemerintah telah menetapkan dan mempertahankan kecukupan luas kawasan hutan dalam daerah aliran sungai dan/atau pulau dengan sebaran yang proporsional.

Keberadaan hutan juga bukan hanya sebagai penyangga ekologi dunia akan tetapi juga penyangga ekonomi rakyat dimana hutan tersebut berada, artinya selain fungsi ekologis yang melekat pada hutan, hutan juga memiliki fungsi ekonomis, dimana pengaturan fungsi ekonomis dari hutan ini di Indonesia dinaungi ketentuan konstitusional yaitu Pasal 33 Undang-Undang Dasar 1945, dimana bumi, air dan kekayaan alam termasuk di dalamnnya dikuasai oleh negara dn diperuntukkan sebesar-besarnya untuk kemakmuran rakyat. 
Pengelolaan hutan harus berasaskan pemanfaatan untuk menjamin dan menjaga kelestarian serta keseimbangan hutan. Undang-Undang Nomor 41 Tahun 1999 Tentang Kehutanan, menempatkan asas manfaat dan lestari, kerakyatan dan keadilan sebagai sendi atau penyangga pelestarian hutan. Sebagaimana disebutkan dalam Pasal 2 Undang-Undang Nomor 41 Tahun 1999 bahwa penyelenggaraan kehutanan harus berasaskan kemanfaatan dan kelestarian, kerakyatan, keadilan, kebersamaan, keterbukaan, dan keterpaduan.

Selanjutnya dalam Pasal 3 Undang-Undang Nomor 41 Tahun 1999, disebutkan bahwa penyelenggaraan kehutanan bertujuan untuk sebesar-besar kemakmuran rakyat yang berkeadilan dan berkelanjutan dengan: (1) menjamin keberadaan hutan dengan luasan yang cukup dan sebaran yang proporsional; (2) mengoptimalkan aneka fungsi hutan yang meliputi fungsi konservasi, fungsi lindung, dan fungsi produksi untuk mencapai manfaat lingkungan, sosial, budaya, dan ekonomi, yang seimbang dan lestari; (3) meningkatkan daya dukung daerah aliran sungai; (4) meningkatkan kemampuan untuk mengembangkan kapasitas dan keberdayaan masyarakat secara partisipatif, berkeadilan.

Pembangunan kehutanan merupakan bagian dari pembangunan nasional, dengan demikian pembangunan kehutanan di Kota Palopo harus searah dan setujuan dengan pembangunan nasional. Pembangunan kehutanan Kota Palopo telah memberikan sumbangan bagi pembangunan nasional maupun daerah, baik dilihat dari pendapatan devisa negara, penyerapan tenaga kerja, pelestarian lingkungan hidup, serta peningkatan kesejahteraan masyarakat sekitar hutan.

\section{Rumusan Masalah}

Berdasarkan latar belakang di atas, maka penulis merumuskan beberapa permasalahan sebagai berikut:

1. Apakah tugas dan wewenang Dinas Kehutanan dan Perkebunan Kota Palopo terlaksana secara efektif sesuai Peraturan Daerah Nomor 3 Tahun 2008?

2. Faktor-faktor apakah yang mempengaruhi efektifitas pelaksanaan tugas dan wewenang Dinas Kehutanan dan Perkebunan Kota Palopo?

Tujuan penelitian ini adalah sebagai berikut:

1. Menganalisis efektifitas pelaksanaan tugas dan wewenang Dinas Kehutanan dan Perkebunan Kota Palopo menurut Peraturan Daerah Nomor 3 Tahun 2008.

2. Menganalisis faktor-faktor yang mempengaruhi pelaksanaan tugas dan wewenang Dinas Kehutanan dan Perkebunan Kota Palopo.

Manfaat penelitian ini adalah sebagai berikut:

1. Dari segi teoritis, studi ini diharapkan akan memberikan konstribusi bagi pengembangan ilmu hukum khususnya terhadap hukum tata negara dan pemerintahan daerah.

2. Dari segi praktis, studi ini diharapkan dapat memberikan masukan bagi pemerintah kabupaten/kota dalam mengefektifkan pelaksanaan tugas dan 
wewenang Dinas Kehutanan dan Perkebunan dalam menjaga kelestarian lingkungan hidup dan sumber daya alam.

\section{B. METODE PENELITIAN}

\section{Tipe Penelitian}

Dalam penelitian ini digunakan tipe penelitian sosio yuridis atau gabungan antara penelitian normatif dan empiris yakni penelitian yang mencermati konsep hukum dan pelaksanaannya di lapangan atau bekerjanya hukum di masyarakat serta berusaha memberikan deskripsi atau gambaran mengenai fakta dan kejadian yang berhubungan dengan tugas dan wewenang Dinas Kehutanan dan Perkebunan Kota Palopo menurut Peraturan Daerah Nomor 3 Tahun 2008. Pendekatan secara sosiologis mengenai tugas dan wewenang Dinas Kehutanan dan Perkebunan yang berimplikasi terhadap pelayanan masyarakat sebagai variabel sosial yang empirik.

\section{Lokasi Penelitian}

Penelitian ini dilaksanakan di Kota Palopo tepatnya pada Dinas Kehutanan dan Perkebunan Kota Palopo. Pemilihan obyek penelitian didasarkan atas pertimbangan, bahwa wilayah ini memiliki kawasan hutan yang paling luas di Propinsi Sulawesi Selatan dengan keragaman fungsi kawasan hutannya, dimana masyarakatnya menggantungkan hidup dari sumber daya hutannya, sehingga pengelolaan hutan oleh Dinas Kehutanan dan Perkebunan sangat penting untuk diefektifkan agar dapat meningkatkan kesejahteraan masyarakat di Kota Palopo.

\section{Populasi dan Sampel}

Populasi dalam penelitian adalah seluruh pegawai pada Dinas Kehutanan dan Perkebunan Kota Palopo yang dianggap mengetahui seluk beluk mengenai pelaksanaan tugas dan wewenang Dinas Kehutanan dan Perkebunan Kota Palopo; Lembaga Swadaya Masyarakat (LSM); dan tokoh masyarakat.

Selanjutnya sampel dalam penelitian ini ditentukan sebanyak 100 responden dari seluruh kecamatan di Kota Palopo dengan menggunakan teknik purposive sampling, mengingat jumlah populasi yang sangat banyak dan sumber data sangat luas, dimana responden terdiri dari: pegawai Dinas Kehutanan dan Perkebunan Kota Palopo; Lembaga Swadaya Masyarakat (LSM); dan tokoh masyarakat.

\section{Jenis dan Sumber Data}

Jenis data yang diperlukan dalam penelitian ini meliputi data primer dan data sekunder. Kedua jenis data tersebut didapatkan melalui sumber, yaitu:

1. Data primer yaitu data lapang yang diperoleh langsung dari responden yang terdiri dari: pegawai Dinas Kehutanan dan Perkebunan Kota Palopo, tokoh masyarakat dan anggota LSM.

2. Data sekunder yaitu data yang diperoleh dari penelusuran bahan pustaka berupa buku-buku, artikel ilmiah, hasil penelitian, peraturan pemerintah, 
referensi-referensi hukum, peraturan perundang-undangan di bidang pemerintahan daerah, dan sumber lain yang relevan dengan penelitian ini.

\section{Metode Pengumpulan Data}

Untuk mendapatkan data yang diperlukan dalam penelitian ini, digunakan instrumen pengumpulan data sebagai berikut:

1. Angket (kuesioner)

Dalam penelitian ini digunakan angket yang berbentuk terbuka dan tertutup sebagai penjabaran dari indikator variabel-variabel penelitian. Pada angket tertutup disiapkan berbagai alternatif jawaban sehingga responden dapat memilih salah satu alternatif jawaban yang tersedia pada setiap pertanyaan. Sedangkan pada angket terbuka tidak disediakan alternatif jawaban. Hal ini dimaksudkan untuk memberikan kesempatan kepada responden mengungkapkan pendapatannya. Pengumpulan kuesioner dalam penelitian ini dimaksudkan untuk mendapatkan data primer yang berkaitan dengan pelaksanaan tugas dan wewenang Dinas Kehutanan dan Perkebunan Kota Palopo serta variabel-variabel lain yang terkait langsung dengan obyek penelitian ini.

\section{Wawancara}

Penggunaan teknik wawancara bertujuan untuk mendapatkan data yang belum termuat dalam angket. Untuk memudahkan pelaksanaannya dilakukan secara terstruktur dengan menggunakan pedoman wawancara.

\section{Studi Dokumen}

Studi dokumen dilakukan melalui proses identifikasi peraturan perundangundangan yang berkenaan dengan tugas dan wewenang Dinas Kehutanan dan Perkebunan Kota Palopo.

\section{Teknik Analisis Data}

Data yang diperoleh melalui kegiatan penelitian, diidentifikasi dan dikelompokkan menurut karakteristik tujuan penelitian, kemudian dianalisis secara kualitatif deskriptif yaitu menguraikan, menjelaskan dan menggambarkan berbagai faktor yang terungkap dengan pendekatan yuridis yang berkaitan dengan tugas dan wewenang Dinas Kehutanan dan Perkebunan Kota Palopo. Sedangkan hasil kuisioner berupa angket dianalisis secara kualitatif dalam bentuk tabulasi frekuensi dan distribusi persentase dengan rumus sebagai berikut:

$$
\mathrm{P}=\frac{\mathrm{f}}{\mathrm{N}} \times 100 \%
$$

Keterangan :

$\mathrm{P} \quad=$ Persentase

$\mathrm{F} \quad=$ Frekuensi

$\mathrm{N} \quad=$ Jumlah responden. 
$100 \%=$ Angka pembulat.

\section{PEMBAHASAN DAN HASIL PENELITIAN}

\section{Pembahasan}

Pelaksanaan tugas-tugas Dinas Kehutanan dan Perkebunan dalam rangka pengelolaan sumberdaya kehutanan dan perkebunan ditunjang oleh ketersediaan sumberdaya manusia yang terdistribusi dalam bidang tugas pembangunan lingkup Dinas Kehutanan dan Perkebunan Kota Palopo. Selain itu, komposisi staf yang ada berasal dari disiplin ilmu yang beragam, sehingga potensi ini diharapkan mampu menjadi kolaborasi yang efektif dalam rangka pelaksanaan tugas-tugas bidang kehutanan dan perkebunan Kota Palopo. Sebagai gambaran, berikut ini diuraikan dalam tabel tentang keadaan kepegawaian pada Dinas Kehutanan dan Perkebunan Kota Palopo.

Rencana strategis dinas memuat tentang visi, misi, tujuan dan sasaran pembangunan bidang kehutanan dan perkebunan Kota Palopo untuk jangka waktu 5 tahun 2008 sampai 2013. Visi pembangunan kehutanan dan perkebunan Kota Palopo dirumuskan sebagai: mewujudkan pemanfaatan sumberdaya kehutanan dan perkebunan dengan pola pengelolaan yang terpadu dan berkelanjutan. Visi inilah yang menjadi landasan pencapaian kinerja dinas yang kemudian diturunkan ke dalam misi pembangunan.

Adapun pengaruh budaya hukum terhadap pelaksanaan tugas dan wewenang Dinas Kehutanan dan Perkebunan Kota Palopo, dapat dilihat pada tabel berikut ini.

Tabel 15. Jawaban responden tentang pengaruh budaya hukum terhadap efektifitas pelaksanaan tugas dan wewenang Dinas Kehutanan dan Perkebunan Kota Palopo

\begin{tabular}{|c|c|c|c|}
\hline No. & Kategori Jawaban & Frekuensi & Persentase \\
\hline 1. & Berpengaruh & 58 & 58 \\
2. & Kurang berpengaruh & 31 & 31 \\
3. & Tidak berpengaruh & 11 & 11 \\
\hline \multicolumn{2}{|c|}{} & 100 & 100 \\
\hline
\end{tabular}

Sumber: Data Primer, 2013

Berdasarkan data pada tabel di atas menunjukkan pengaruh budaya hukum terhadap efektifitas pelaksanaan tugas dan wewenang Dinas Kehutanan dan Perkebunan Kota Palopo ditanggapi bervariatif, yakni yang menyatakan berpengaruh sebanyak 58 orang responden, yang menyatakan kurang berpengaruh sebanyak 31 orang responden, dan menyatakan tidak berpengaruh sebanyak 11 orang responden. Hal ini berarti pada umumnya responden menyatakan berpengaruh sehingga dapat dikatakan bahwa budaya hukum mempunyai 
pengaruh terhadap efektifitas pelaksanaan tugas dan wewenang pada Dinas Kehutanan dan Perkebunan Kota Palopo.

\section{Sarana dan prasarana}

Faktor sarana dan prasarana adalah faktor pendukung dalam pelaksanaan tugas dan wewenang Dinas Kehutanan dan Perkebunan Kota Palopo. Ketersediaan sarana dan prasarana yang memadai diharapkan dapat memperlancar mekanisme dari proses kerja Dinas Kehutanan dan Perkebunan Kota Palopo dalam mewujudkan pemerintahan yang baik.

Pelimpahan kewenangan tidak disertai dana, sarana dan prasarana yang memadai tentu tidak akan terlaksana secara efektif. Pelaksanaan tugas dan kewenangan harus ditunjang pula oleh ketersediaan sumber-sumber daya yang dibutuhkan dalam menyelenggarakan tugas dan kewenangan tersebut. Dalam hal ini harus ada penyusunan konsep perimbangan sumber daya termasuk keuangan, sumber daya manusia, dan sarana dan prasarana. Tanpa adanya penguatan sumberdaya tersebut, maka Dinas Kehutanan dan Perkebunan Kota Palopo akan mengalami over-load dalam tugas-tugasnya, dan kewenangan yang dilimpahkan tidak akan dapat dilaksanakan secara efektif dan efisien. Jika hal ini terjadi, maka pelaksanaan tugas dan wewenang dapat dikatakan mengalami kegagalan.

Adapun pengaruh sarana dan prasarana terhadap efektifitas pelaksanaan tugas dan wewenang Dinas Kehutanan dan Perkebunan Kota Palopo, dapat dilihat pada tabel berikut ini.

Tabel 16. Jawaban responden tentang pengaruh sarana dan prasarana terhadap efektifitas pelaksanaan tugas dan wewenang Dinas Kehutanan

dan Perkebunan Kota Palopo

\begin{tabular}{|c|c|c|c|}
\hline No. & Kategori Jawaban & Frekuensi & Persentase \\
\hline 1. & Berpengaruh & 61 & 61 \\
\hline 2. & Kurang berpengaruh & 32 & 32 \\
\hline 3. & Tidak berpengaruh & 7 & 7 \\
\hline \multicolumn{2}{|r|}{ Jumlah } & 100 & 100 \\
\hline
\end{tabular}

Sumber: Data Primer, 2013

Berdasarkan data pada tabel di atas menunjukkan pengaruh sarana dan prasarana terhadap efektifitas pelaksanaan tugas dan wewenang Dinas Kehutanan dan Perkebunan Kota Palopo ditanggapi bervariatif, yakni yang menyatakan berpengaruh sebanyak 61 orang responden, yang menyatakan kurang berpengaruh sebanyak 32 orang responden, dan menyatakan tidak berpengaruh sebanyak 7 orang responden. Hal ini berarti pada umumnya responden menyatakan berpengaruh sehingga dapat dikatakan bahwa sarana dan prasarana mempunyai pengaruh terhadap efektifitas pelaksanaan tugas dan wewenang pada Dinas Kehutanan dan Perkebunan Kota Palopo. 


\section{KESIMPULAN}

Berdasarkan pembahasan sebelumnya, maka dapat disimpulkan sebagai berikut:

1. Pelaksanaan tugas dan wewenang Dinas Kehutanan dan Perkebunan Kota Palopo terlaksana kurang efektif sesuai Perda No. 3 Tahun 2008, termasuk tugas membantu Walikota dalam penyelenggaraan teknis pemerintahan di bidang kehutanan dan perkebunan, dan begitu pula pelaksanaan fungsi yang juga terlaksana kurang efektif, termasuk: (a) perumusan kebijakan teknis dalam bidang kehutanan dan perkebunan sesuai lingkup tugasnya; (b) pelaksanaan pengawasan dan pelayanan umum; (c) pembinaan terhadap Unit Pelaksana Teknis Dinas; (d) pelaksanaan tugas lain sesuai perundang-undangan yang berlaku.

2. Faktor-faktor yang mempengaruhi efektifitas pelaksanaan kewenangan Dinas Kehutanan dan Perkebunan Kota Palopo adalah: substansi hukum (56\%), struktur hukum (54\%), pengetahuan hukum (59\%), budaya hukum (58\%), dan sarana dan prasarana $(61 \%)$.

\section{E. SARAN}

Berdasarkan kesimpulan di atas, maka peneliti mengajukan beberapa saran sebagai berikut:

1. Untuk mengefektifkan pelaksanaan tugas dan wewenang Dinas Kehutanan dan Perkebunan Kota Palopo, maka sebaiknya Perda Nomor 3 Tahun 2008 direvisi karena peraturan perundang-undangan ini tidak mengatur secara tegas tugas dan wewenang Dinas Kehutanan dan Perkebunan Kota Palopo. Oleh karena itu, para pegawai diharapkan lebih berperan aktif lagi terutama dalam proses pengambilan keputusan dalam pelaksanaan tugas, fungsi, wewenang dan memaksimalkan pelayanan yang baik kepada masyarakat.

2. Faktor substansi hukum, struktur hukum, pengetahuan hukum, budaya hukum, sarana dan prasarana masih perlu ditingkatkan agar pelaksanaan tugas dan wewenang Dinas Kehutanan dan Perkebunan Kota Palopo dapat diefektifkan sehingga pemanfaatan sumber daya kehutanan dan perkebunan dengan pola pengelolaan terpadu dan berkelanjutan dapat diwujudkan di masa akan datang. 


\section{Daftar Pustaka}

Abdurrahman, 2000. Pengantar Hukum Lingkungan Indonesia, Citra Aditya, Bandung.

Achmad, Ali, 2005. Keterpaduan Hukum di Indonesia (Penyebab dan Solusinya), Ghalia Indonesia, Bogor.

Arief, A. 2004. Hutan: Hakikat Dan Pengaruhnya Terhadap Lingkungan. Jakarta: Penerbit Yayasan Obor Indonesia.

Arifin, Arief, 2001. Hutan dan Kehutanan, Kanisius, Yogyakarta.

Bambang Sunggono, 2003. Metodeologi Penelitian Hukum, Raja Grafindo Persada, Jakarta.

Boehmer - Christiansen S. 1994, Policy and Environmental Management. Journal of Environmental Planning and Management 37(1).

Darjadi, L. Dan R. Hardjono. 2006. Sensi-Sendi Silvikultur. Jakarta: Direktorat Jenderal Kehutanan. Departemen Pertanian.

Erick Lobja. 2003. Menyelamatkan Hutan Dan Hak Adat Mayarakat Kei: Yogyakarta: Debut Press.

FWI dan GFW, 2001, Potret Keadaan Hutan Indonesia, Edisi Ketiga, Forest Wacth Indonesia dan Washingtong D.C.: Global Forest Wacth: Bogor.

Gusti I., Ayu, 2005. Upaya Penegakan Hukum Lingkungan (Refleksi Hari Lingkungan Hidup Sedunia 5 Juni).

Hasanu Simon, 2003. Hutan Jati dan Kemakmuran. Jogjakarta: Aditya Media.

Indriyanto. 2006. Ekologi Hutan. Bumi Aksara, Jakarta.

Kardi. W. 2002. Manual Kehutanan. Jakarta: Departemen Kehutanan Republik Indonesia.

Laden, Marpaung, 2005, Tindak Pidana Terhadap Hutan, Hasil Hutan dan Satwa, Erlangga, Jakarta.

Lawrence M. Friedman, 2001. Sistem Hukum: Perspektif Ilmu Sosial. Penerbit Nusamedia, Jakarta.

Maslan, M. Rizal, 2007, Pemerintah Percepat Proses Hukum Illegal Logging, Berita Detik News, Jumat 2 Pebruari, Jakarta.

Noer Fauzi, 2001. Petani Dan Penguasa: Dinamika Perjalanan Politik Agraria Indonesia", Pustaka Pelajar. Yogyakarta.

Nurdjana, 2005. Korupsi dan Illegal Logging Dalam Sistem Desentralisasi, Pustaka Pelajar, Yogyakarta.

Odum, E. HLM. 2003. Dasar-dasar Ekologi. Terjemahan oleh Tjahjono Samingan dari buku Fundamental of Ecology. Yogyakarta: Gadjah Mada University Press.

Pamukardi, Bambang, 2004. Hukum Kehutanan dan Pembangunan Bidang Kehutanan, Raja Grafindo Persada, Jakarta.

Prakosa, M., 1996. Rencana Kebijakan Kehutanan. Aditya Media, Yogyakarta.

Raharjo, Sacipto, 2001. Ilmu Hukum, Citra Aditya Bakti, Bandung. 
Rangkuti, Sundari, 2003, Hukum Lingkungan dan Kebijakan Lingkungan Nasional, Airlangga University Press, Surabaya.

Reza, Suarga, 2005, Pemberantasan Illegal Logging, Optimesme di Tengah Praktik Premanisme Global, Wana Aksara, Jakarta.

Salim H.S, 2006. Dasar-Dasar Hukum Kehutanan, Sinar Grafika, Jakarta.

Simon, Hasanu. 2003. Hutan Jati dan Kemakmuran; Problematika dan Strategi Pemecahannya. Bigraf. Yogyakarta.

Subagyo, Joko, 2000, Hukum Lingkungan Masalah dan Penanggulangan Penegakan Hukum, Raja Grafindo, Jakarta.

Sudikno Mertokusumo, 2001, Perundang-undangan Agraria Indonesia, Yogyakarta, Liberty.

Soemarwoto, 2003. Ekologi Lingkungan Hidup dan Pembangunan. Jakarta: Penerbitan Djambatan

Soerjono, Soekanto, 1986. Metode Penelitian. Raja Grafindo, Jakarta.

2005. Faktor-Faktor yang Mempengaruhi Penegakan Hukum, Raja Grafindo, Jakarta.

Steinling, Hansjung, 2000, Menuju Kelestarian Hutan, Yayasan Obor Indonesia, Jakarta.

Zain, A. Setia, 2006, Hukum Lingkungan Konservasi Hutan, Rineka Cipta, Jakarta.

\section{Peraturan Perundang-undangan:}

Undang-Undang Dasar Negara RI 1945

Undang-Undang Nomor 5 Tahun 1960 Tentang Peraturan Dasar Pokok-Pokok Agraria

Undang-Undang No. 23 Tahun 1997 Tentang Lingkungan Hidup.

Undang-Undang No. 41 Tahun 1999 Tentang Kehutanan.

Peraturan Daerah Kota Palopo Nomor 3 Tahun 2008 Tentang Pembentukan, Organisasi dan Tata Kerja Dinas Daerah Kota Palopo. 